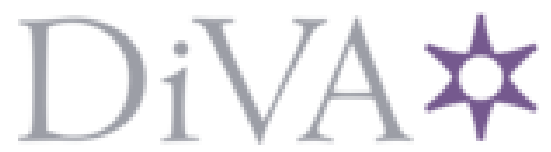

http://www.diva-portal.org

This is the published version of a paper presented at SPIE European Defence and Security, Amsterdam, September 19-23 2014.

Citation for the original published paper:

Andersson, K., Åkerlind, C. (2014)

A review of materials for spectral design coatings in signature management applications.

In: Douglas Burgess; Gari Owen; Harbinder Rana; Roberto Zamboni; François Kajzar; Attila

A. Szep (ed.), Optics and Photonics for Counterterrorism, Crime Fighting, and Defence X; and Optical Materials and Biomaterials in Security and Defence Systems Technology XI (vol. 9253)

SPIE - International Society for Optical Engineering

https://doi.org/10.1117/12.2067167

N.B. When citing this work, cite the original published paper.

Copyright: 2014 Society of Photo Optical Instrumentation Engineers. One print or electronic copy may be made for personal use only. Systematic reproduction and distribution, duplication of any material in this paper for a fee or for commercial purposes, or modification of the content of the paper are prohibited.

Permanent link to this version:

http://urn.kb.se/resolve?urn=urn:nbn:se:fhs:diva-5009 


\title{
A review of materials for spectral design coatings in signature management applications
}

\author{
Kent E Andersson ${ }^{*}$, Christina Åkerlind ${ }^{\mathrm{b}}$ \\ ${ }^{a}$ Finnish National Defence University/Swedish National Defence College, Box 278 05, SE-115 93 \\ Stockholm, Sweden; ${ }^{b}$ Swedish Defence Research Agency SE-581 11 Linköping, Sweden
}

\begin{abstract}
The current focus in Swedish policy towards national security and high-end technical systems, together with a rapid development in multispectral sensor technology, adds to the utility of developing advanced materials for spectral design in signature management applications. A literature study was performed probing research databases for advancements. Qualitative text analysis was performed using a six-indicator instrument: spectrally selective reflectance; low gloss; low degree of polarization; low infrared emissivity; non-destructive properties in radar and in general controllability of optical properties. Trends are identified and the most interesting materials and coating designs are presented with relevant performance metrics. They are sorted into categories in the order of increasing complexity: pigments and paints, one-dimensional structures, multidimensional structures (including photonic crystals), and lastly biomimic and metamaterials. The military utility of the coatings is assessed qualitatively. The need for developing a framework for assessing the military utility of incrementally increasing the performance of spectrally selective coatings is identified.
\end{abstract}

Keywords: Spectral Design, Signature Management, Camouflage, Military Utility, Military-Technology, Coating

\section{INTRODUCTION}

In Swedish defense policy ${ }^{1}$ focus has again widened from the focus in recent years on force protection in asymmetric expeditionary scenarios, to include national security. Military capabilities are assessed to be evolving towards high-end technology and a need for more competent personnel - at the cost of volume. In turn, fewer and more expensive platforms mean an increased interest in effect, of course, but also mobility. Mobility is often achieved by decreasing weight at the expense of less armor and the decreasing force protection capability is in turn compensated for with active Electronic Warfare systems and camouflage and deception means - i.e. systems for Signature Management. In parallel there is rapid development in multispectral sensor technology and a proliferation among non-state actors of advanced optronic, infrared and microwave sensors - increasing the threat to Swedish Armed Forces in international operations. ${ }^{2}$ Both factors add to the utility of developing new more effective solutions for signature management. The need to camouflage soldiers is high in any event, and the requirement to conduct both expeditionary missions and be prepared for national protection scenarios drives the need for adaptive signatures of platforms and hence the need for Signature Management Technology (SMT).

Any property, or a combination of properties, of an object, that makes it distinguishable from its immediate background by a sensor defines the object signature. ${ }^{3}$ However, this study is limited to the signature originating from electromagnetic interaction with the surface of an object. In addition, now that the need for SMT increasingly includes the infrared spectrum, there is a great demand for solutions meeting the requirements from visible through to long wavelength thermal infrared regions simultaneously. Furthermore, the need to adapt the signature to the full range of missions, in

\footnotetext{
*kent.andersson@fhs.se; phone 46855342836 ; fax 46855342598
}

Optics and Photonics for Counterterrorism, Crime Fighting, and Defence X; and Optical Materials and Biomaterials in Security and Defence Systems Technology XI, edited by Douglas Burgess, Roberto Zamboni, et al., Proc. of SPIE Vol. 9253, 92530Y · (c) 2014 SPIE · CCC code: 0277-786X/14/\$18 · doi: 10.1117/12.2067167 
international as well as national scenarios, also increases the benefit of controllable signatures. The ability to actively control - multispectrally - the signature of an object, such as a combat vehicle, is thus sought after, but very limited.

Spectral design is the ability to create a desired spectral optical response from a surface in favor of the application of interest by choosing suitable materials and structures. The technique is used in several military applications: e.g. the optical filter on head-up displays, laser protective coatings on optics and heat radiation control. When using spectral design for SMT purposes the objective is to tune the spectral appearance of an object in support of military tactics. In some contexts a military object should be seen, e.g. for show of force or for deception. The most challenging case, however, is camouflage, i.e. trying to minimize the contrast between an object and its immediate background in those parts of the spectrum where the threat sensors are sensitive. Thus, the military effectiveness of SMT is related to the threat sensor capability and is often measured in distance to detection or time before detection. Meanwhile, emission in the remainder of the spectrum should, if possible, be optimized for emission of the excessive heat. ${ }^{4}$

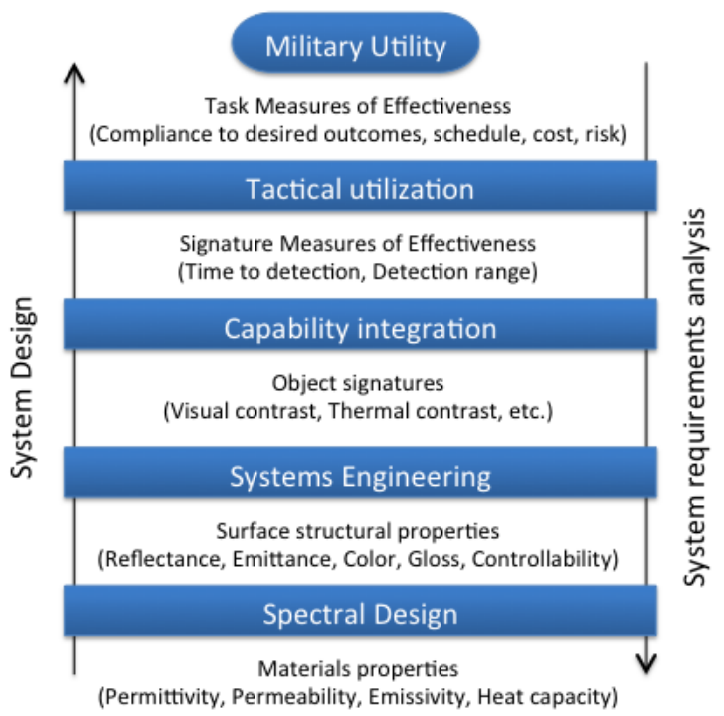

Figure 1. The illustration is a model of the spectral design leg of a signature management process seen as a balancing of needs and design choices in several activities at different system levels. When designing a capability, spectral design utilizes materials with favorable properties to obtain desired structural properties of surfaces in a technical system. System engineering activities balance surface properties with other design measures to obtain a desired object signature. When the object has been integrated into a capability, with proper techniques and procedures for its use, desired signature measures of effectiveness could be achieved. Ultimately proper tactical utilization of the system's capability gives effective support to accomplish the mission militarily. Only then does spectral design have military utility. When analyzing system requirements, the process is traversed in the other direction.

However, the signature of an object in a real environment is complex. Apart from the surface, reflectance and specular properties, it also depends on several factors such as the size of the object, the wavelength of the incident light, its polarization, and also on shadows and atmospheric phenomena. In order to design the signature and possible controllability, with the aid of Systems Engineering, the requirements process has to start with the object in its operational environment. The aim is to give the system designers the freedom to optimize the signature by balancing construction methods with chosen surface properties. ${ }^{3}$ Here one must also balance signature management with other protection measures, such as physical and electronic warfare protection. ${ }^{5}$ Finally, for a signature management system to have real military value you must know your signature; you must have a tactical concept for how to use it and the ability to adapt it rapidly to the tactical situation. Thus the process of designing a system with signature management capability, starting from a spectral design activity, is a complex one and is captured in Figure 1. Turning the process around, the figure also illustrates the equally complex process of formulating relevant requirements for spectral design and material properties. 
Research into materials with the potential to be used in spectral design for SMT applications in the optical and thermal spectra is extensive. Apart from the military applications, it covers smart textiles, solar energy, "cool roofs", decorative coatings, heat control of satellites etc. By exploiting these advances in the future, it may be possible to use spectral design to satisfy the new survivability requirements of signature management.

The work presented in this paper is a first effort in adding a military-technological perspective to spectral design for signature management, i.e. to assess the military utility. The aim is to review what types of materials and coating techniques are available for spectral design purposes and to get a rough idea what their utility is for SMT. Firstly, there is an introduction of terminology used and the desired characteristics of a spectral design coating. In order to limit and to focus the survey the use case is multispectral optical camouflage, i.e. reducing the contrast with the background. In the next section of the paper results are presented and discussed. Finally a summary of results, conclusions and a discussion on future work are presented.

\subsection{Terminology and Physical quantities}

Electromagnetic radiation (light) of some wavelength, $\lambda$, incident on an optically thin coating (thin film) is reflected, absorbed or transmitted, hence $I(\lambda)=R(\lambda)+A(\lambda)+T(\lambda)=100 \%$, where $I(\lambda)$ is the intensity of the incident light, $R(\lambda)$ is the reflectance, $A(\lambda)$ is the absorptance and $T(\lambda)$ is the transmittance. If Maxwell's equations are used to solve the boundary problem of a propagating wave at the surface between two media the Fresnel reflection coefficients are obtained,

$$
r_{p}=\frac{N_{1} \cos \left(\theta_{i}\right)-N_{0} \cos \left(\theta_{t}\right)}{N_{1} \cos \left(\theta_{i}\right)+N_{0} \cos \left(\theta_{t}\right)}, r_{s}=\frac{N_{0} \cos \left(\theta_{i}\right)-N_{1} \cos \left(\theta_{t}\right)}{N_{0} \cos \left(\theta_{i}\right)+N_{1} \cos \left(\theta_{t}\right)} \text { and } R(\lambda)=\boldsymbol{r} \cdot \boldsymbol{r}^{*}
$$

where $r_{p}$ is the reflection coefficient for light polarized parallel and $r_{s}$ for light polarized perpendicular to the plane of incidence, respectively. These expressions show the relationship between the observable reflectance of a surface and optical properties, since $N_{1}=n_{1}+i k_{1}$ is the complex refractive index of the coating material and $N_{0}$ is that of the ambient air. In a dielectric (non-absorbing) material the refractive index is real valued. $\theta_{i}$ is the angle of incidence to the surface normal and $\theta_{t}$ is the angle to the normal for refracted, transmitted, light.

Light reflected from a smooth surface, like a mirror, is specular, i.e. the angle of reflection is the same as the angle of incidence. Light reflected from a rough surface is diffuse, i.e. scattered in all directions. In SMT context the former surface is denoted glossy and the latter as low gloss.

If the $\mathrm{x}$ - and $\mathrm{y}$ - components of the electric field vector of a light wave propagating in $\mathrm{z}$-direction are completely correlated the light is said to be totally polarized. If there is no correlation the light is said to be unpolarized, like from the sun or ordinary lamps. ${ }^{6}$ Polarization features arise from the geometrical orientation, shape, shading and roughness of an object surface. In general, man-made objects with smooth surfaces have more defined polarization signatures than natural objects and tend to take on a polarized component in reflected or emitted radiation. ${ }^{7}$ The ratio between the intensity of polarized light and the total intensity of light irradiated from a surface is denoted the Degree of Polarization (DoP). ${ }^{6}$

The radiaton emitted from a perfect blackbody, i.e. a surface emitting maximum possible energy, depends on wavelength and the absolute surface temperature $T$ of an object. It is expressed through Planck's radiation law as the spectral radiant exitance, $E_{b b}(\lambda, T)$, through

$$
E_{b b}(\lambda, T)=\frac{c_{1}}{\lambda^{5}\left(e^{\frac{c_{2}}{\lambda T}}-1\right)}\left(\mathrm{Wm}^{-2} \mu \mathrm{m}^{-1}\right)
$$


where $c_{1 \text { and }} c_{2}$ are radiation constants, $c_{1}=3,7418 \times 10^{8} \mathrm{Wm}^{-2} \mu \mathrm{m}^{4}$ and $\mathrm{c}_{2}=1,4388 \times 10^{4} \mu \mathrm{m} \mathrm{K}$. In practice most surfaces are not black and hence are called gray bodies. ${ }^{8}$ The Emittance of a surface is obtained by integrating over all wavelengths for a specific temperature. The ratio between a surface gray body emittance and that of a blackbody is denoted Emissivity, $\varepsilon$. Hence, by designing the surface emissivity it is possible to tune an objects apparent temperature to that of the background.

\subsection{Desired characteristics for coatings in multispectral low signature applications}

From the definition of signature we find that it is partly defined by the sensitivity spectrum of the threat sensor. One justification for the research is, however, that sensors are becoming increasingly multispectral and hence we will not limit our interest to particular parts of the electromagnetic spectrum from the sensor sensitivity point of view. The aim is to design coatings that control emissions resulting from a combination of incident solar radiation and thermal selfemitted radiation. We will, however, assume that the sensors are used at such a distance that the attenuation and scattering of electromagnetic radiation from the object, due to interaction with molecules or aerosols in the atmosphere, greatly affect the detected intensity in some parts of the spectrum. From this point of view it is useful to discuss the optical properties of spectrally selective coatings in four wavelength regions; the UV-VIS-NIR region $0.2-2.5 \mu \mathrm{m}$, the MWIR-region 3-5 $\mu \mathrm{m}$, the LWIR $8-14 \mu \mathrm{m}$ and the radar region $>1 \mathrm{~mm} .{ }^{8,9}$ The situation is illustrated in Figure 2 below.

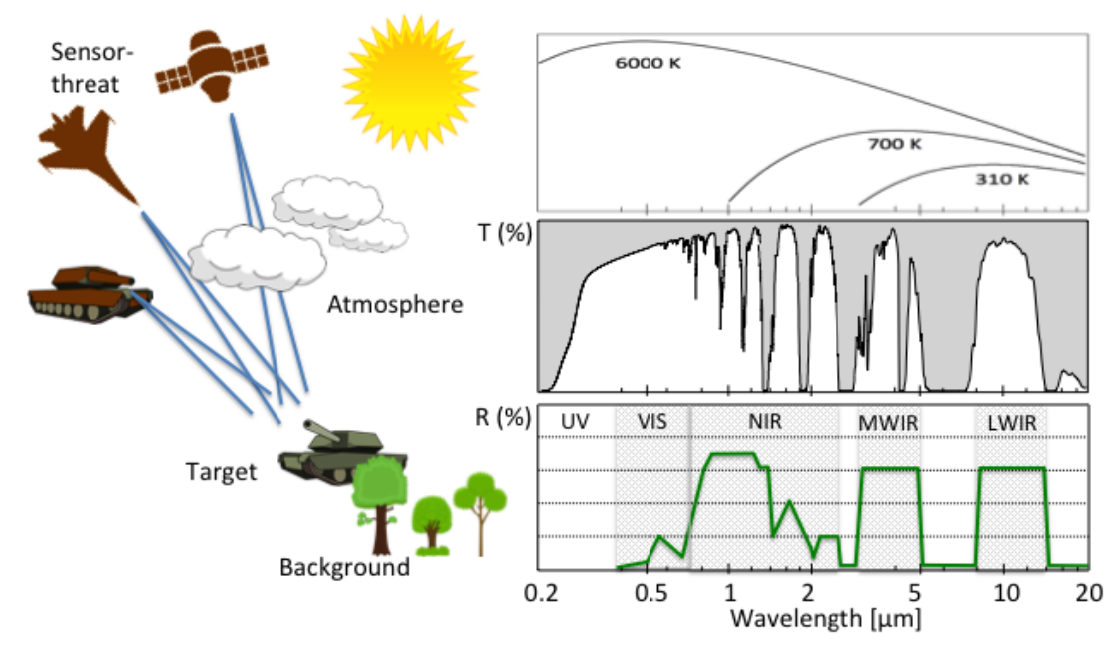

Figure 2. The picture to the left illustrates a typical detection/camouflage scenario. The right upper diagram shows the blackbody radiation spectra of the illuminating sun, the target exhaust and a soldier respectively. The middle diagram shows the transmittance spectra of the atmosphere. The atmospheric "windows" identified for detection; VIS, NIR, MWIR and LWIR are indicated in the lower diagram together with the "ideal" emission spectra of a coating used to camouflage a ground target in the situation depicted.

In the UV-VIS-NIR region the electromagnetic radiation from an object is dominated by reflected light from the sun, the moon, the stars or from an artificial light source. In this interval it is, therefore, relevant to study the materials reflective properties. Now, the sensors in UV-VIS-NIR are sensitive to spectral variations in the detected radiation, e.g. the human eye or any imaging device such as a camera. Therefore, low signature requires the reflectance of an object surface to be spectrally adapted to that of the object background. Our first characteristic of a potentially good coating for signature management purposes is, therefore, spectrally selective reflectance, close to that of the background. This usually means $\mathrm{R}_{\mathrm{VIS}}<15 \%, \mathrm{R}_{\mathrm{NIR}(\text { green) })}: 45-60 \%, \mathrm{R}_{\mathrm{NIR}(\text { brown) }}: 10-25 \%$ and $\mathrm{R}_{\mathrm{NIR}(\text { black })}: 5-10 \%$ in accordance with earlier studies. ${ }^{10-12}$ The background response indicated in Figure 2 is chlorophyll-like in VIS-NIR.

There are, however, a further two parameters to take into account in the UV-VIS-NIR region. A glossy surface reveals an object regardless of spectral adaptability. Hence a second required characteristic is low gloss. ${ }^{3(\mathrm{p} 83)}$ 
Furthermore, there are reports of development in Spectropolarimetric imaging. These sensors are sensitive to the polarization state of light irradiated from a surface, in addition to spectral intensity, and show potential for more robust detection of objects in a complex and cluttered environment. ${ }^{7}$ Low degree of polarization is, therefore, proposed as a third characteristic.

In the MWIR or LWIR regions the electromagnetic radiation from an object is dominated by its own thermal radiation, which is why it is relevant to study material emissivity in this part of the spectrum. The emissivity of naturally occurring backgrounds, such as vegetation, rock or sand is almost always higher than man-made objects, especially those made of metal. However, since the objects we would like to camouflage are often hotter than their surroundings, this is usually a good thing. The apparent thermal contrast with the background stays small. Low infrared emissivity is, therefore, considered to be a fourth characteristic of low signature materials in this study. This value can easily be increased as needed and in this work an emissivity of about 0.4-0.6 is considered to be acceptable, in accordance with, for example, Hallberg et al. ${ }^{10(\mathrm{p} 7)}$

In the radar wavelength region a target is detected by illuminating the object and detecting the reflected energy. A signature management coating for optical wavelengths must therefore not interfere with the targets spectral design for radar wavelengths. ${ }^{13}$ In most applications this means the reflectance of the coating should be very low. This can be achieved by making the coating very thin and transmissive, deposited on top of a radar absorbing coating, or by using a material with high absorption. In some use cases, however, the radar reflectance should instead be high, e.g. when deposited on the cockpit glass dome of a combat aircraft. ${ }^{\dagger}$ Our fifth indicator of a low signature coating material relates to the radar spectrum and, due to the contradicting requirements of different applications, the indicator is formulated as non-destructive properties.

From the arguments above we find that, in order to be really useful, the signature system of a mobile military object has to be adaptable to environment, background, weather, threat level and mission. One way of meeting these demands is to use exchangeable skins, camouflage nets, uniforms etc. If, however, the need to change signature is within the framework of a mission, the situation requires the surface coating to have adjustable optical properties. Hence, our sixth characteristic of a coating for signature management purposes is controllability at optical wavelengths. Hitherto sensors have not been very selective, spectrally, in the thermal infrared part of the spectra, but there is a development towards multiband detectors.

\section{METHOD AND LITERATURE}

The survey was conducted as a literature search followed by a qualitative assessment of utility, using the six characteristics of a coating for multispectral optical SMT identified above as indicators. The databases Web of Science, Scopus, CSA and SPIE were chosen and probed for articles. ${ }^{\ddagger}$ Articles were excluded if their focus was clearly on other phenomena, properties or applications than those of interest to this study, or if the article focused on measurement techniques. In a first iteration the exclusion criteria were applied to titles and in a second to abstracts. Publically available research reports with experimental data from the Swedish Defence Research Agency, FOI, are considered of

\footnotetext{
† If the glass dome were to transmit radar wavelengths the inside of the cockpit would make an effective radar reflector. A thin metallic film on the glass surface reflects radar waves in all directions but transmits visible light.

₹ Modifications of the following search string was used: (review OR characterisation OR measurement*) AND (reflect* OR "low emissive*" OR dielectric OR diffuse OR lambertian OR "low gloss" OR infrared OR IR OR TIR OR optical OR tunable OR adapt*) AND (chromogenic* OR "thermo chromic" OR "electro chromic" OR multilayer OR metamaterial* OR pigment* OR polymer* OR "nano composite*" OR tailor*) AND (surface* OR coating* OR material* OR structure*) AND (BRDF OR scatterometry OR camouflage OR "signature management").
} 
scientific quality and are used if relevant. Review articles, written by established researchers in the respective fields studied, were used to narrow the scope of the survey back in time.

\section{RESULTS AND DISCUSSION}

Designs for spectrally selective coatings can be divided into two categories, paints and pigments or periodic surface structures. ${ }^{14(\mathrm{p} 18)}$ The latter are further divided into subcategories in order of increasing complexity: one-dimensional structures, multidimensional structures (including photonic crystals), and lastly biomimic and metamaterials.

\subsection{Paints and pigments}

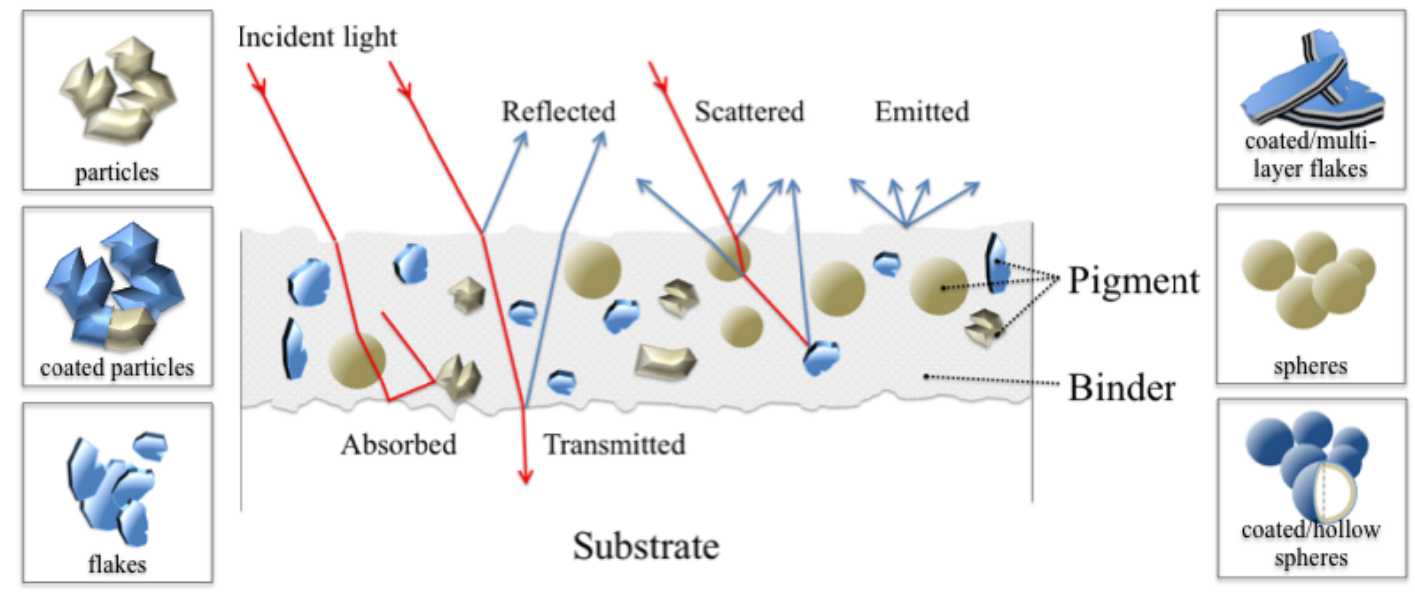

Figure 3. In the middle there is an illustration of a typical paint coating system and possible interactions with light. The paint consists of a mixture of pigments in a binder applied to a substrate. To the left and right pigments of different complexity are depicted.

As an introduction ${ }^{15}$ to paint coating systems, they generally consist of pigments and a binder on a substrate, see Figure 3 , and the pigment material, the particle size, the particle shape and the paint binder are all important parameters when designing its spectral properties. Apart from absorption within the coating and reflection at the boundaries, the particle size and shape affect the optical response of a material through backscattering, a phenomenon commonly used in spectral design of VIS-NIR spectrally selective coatings. The emission from the surface due to backscattering will increase if the ratio between the refractive index of the particles and of the binder increases. Consequently, in order to be able to adjust the paint properties with a suitable mix of pigments, binders should also exhibit as low absorption as possible throughout the region of interest. Of course the binder must also provide adhesion to the substrate (not a requirement in temporary paints), protect the pigments and preserve their infrared properties.

In 1993 Wake and Brady summarized development in VIS-NIR spectral design coatings and addressed some of the challenges of extending spectral requirements to the Thermal IR region (TIR). ${ }^{15}$ They stated that the traditional organic and inorganic pigments used to damp reflectance in VIS cannot be used, since they also absorb TIR and thus cause high emissivity. From extensive experiments they learnt that exploiting scattering from large pigment particles is restricted in TIR. The size needed would risk making a coating "visibly coarse and would affect color uniformity, dirt retention, and other important performance properties"15,16 A possible approach, Wake \& Brady conclude, is to use metal flake pigments, e.g. aluminum, which provide strong reflection across the visible and infrared spectrum. Flaked metal pigments are chosen over particle shaped ones since they maintain high reflectivity when compounded in a film, due to their relatively large flat surfaces.

Hallberg et al. pick up on this line of study comparing different types of pigment for low emissive applications ${ }^{10}$. They study highly reflective $\mathrm{Al}, \mathrm{Ag}$ and $\mathrm{Cu}$ flake pigments, uncoated or coated with dielectrics. However, since these 
materials also are highly reflective in VIS, they conclude that, unfortunately, these types of pigments reduce the camouflage performance in the visible part of the spectrum. An anti-reflectance treated $\mathrm{TiO}_{2} / \mathrm{Au} / \mathrm{TiO}_{2}$ flake pigment was also produced using magnetron sputtering and dividing the thin film into flakes when removed from the substrate. A paint meet transmittance requirements in VIS, but not low emittance requirements. Hallberg et al. conclude that among pure metal pigments, only Al, in combination with polymer-based binders, gives acceptably low emissivity. They report that the most probable explanation is that $\mathrm{Al}$ naturally forms a stable oxide protecting it from deteriorating chemical reactions with the binder. Furthermore, the level of emissivity can be adjusted easily by tuning the Al flake density in the paint. A semiconductor like Si is heavily absorbent of wavelengths shorter than the bandgap wavelength, for Si this is below $1.1 \mu \mathrm{m}$. Hence, it looks black in VIS and can be used to lower reflectivity.

A study of the use of metal-coated cenospheres as pigments in low emissive paints was conducted by Hedborg Karlsson \& Hallberg et al. ${ }^{10,17,18}$ A cenosphere is an inert and hollow sphere consisting of silicon dioxide and aluminum oxide. Coated spheres showed much the same properties as the respective metal powder in both VIS and IR, but when mixed with a binder the absorption in LWIR was much too high. One hypothesis was that the spheres fell to the bottom of the paint. $^{\S}$ The need for a new binder or a more inert metal coating was identified. The conductivity of the Al-coated cenospheres was, however, found to be lower than that of corresponding metal pigments, which is why the authors expect the radar transmittance to be better. Metal flakes have a tendency to agglomerate and thus cause high reflectivity in RR.**

A large portion of the hits from the database search for developments in recent years in pigments with NIR-reflecting properties concern the roofing industry and originate from an interest in producing "cool roofs" for energy saving purposes. Researchers report coatings with pigments yielding different colors while still exhibiting NIR-reflectance in the $70-90 \%$ range. ${ }^{19-24}$ The substrates are generally clay and the coatings are applied through engobing.

In the military sector there is great interest in lowering the signature of soldiers in the VIS-NIR wavelength region where night vision goggles are becoming a high volume threat. ${ }^{2,25-32}$ The blending of artificial and natural fibers in fabric for modern uniforms normally gives NIR-reflectance that is too high when compared to natural background, ${ }^{33}$ which is why new pigments are being developed for lowering NIR-reflectivity, such as NIR-absorbing Vat dyes. ${ }^{34}$ Washing, though, seems to deteriorate performance if using textile printing techniques and paste with low emissive pigments. Incorporating pigments in the polymer fiber at the fiber forming process, however, seems to be feasible since this can be combined with textile printing with reactive dyes for VIS-NIR performance.

Mao et al. recently presented emissivity as low as 0.63 in coated cotton fabric using pigments of $\mathrm{Al}$ and $\mathrm{La}$ doped $\mathrm{ZnO} .^{35}$ In another report Mao et al. show a lowering of the cotton fabric emissivity using a coating with $\mathrm{W}$-doped $\mathrm{VO}_{2}$ pigments. They were also able to show that this kind of fabric changed emissivity spontaneously with changes of ambient temperature. ${ }^{36}$ Mao et al. suggest using both coatings on uniforms for infrared camouflage. No other indicator characteristics than LWIR emissivity is reported. There are no comments on degradation due to wear and tear. Pigments with chromogenic properties would be of interest for the desired controllability aspect of surfaces. There are also reports on TC-pigments being characterized. ${ }^{36,37}$ This development is of interest in spectral design for thermal control purposes, especially on simple lightweight systems like uniforms.

Wake and Brady reported on the impact of binders in paint coating systems in 1993 and suggest selecting pigments with refractive indices and particle size and shape that scatter light effectively in bands where resins absorb. ${ }^{15}$ Resins and binders with weak absorption in parts of TIR of interest have been studied by several researchers: e.g. polyvinylidene

$\S$ Personal comm. with Thomas Hallberg 12-08-2014

** Ibid 
fluoride $^{38}$; dimethyl silicone resins ${ }^{39}$; inorganic silicate oligomers-form polymers ${ }^{40}$; polyurethanes, vinyl polymers, silicone polymers, epoxy resins, polyethylene and chlorinated polyolefine ${ }^{41}$.

There are also a few studies that have reported on complete paint coating systems for optically multispectral SMT. These results can serve as a snapshot of current developments. The reported performance of these coatings, filtered using the six-indicator instrument, is presented in table 1. Note that the pigments used are based on Al flakes. Hallberg et al. comment on the binder that "except for the IR reflective pigment and the binder, the paint should include many other ingredients or additives which will improve various properties of the paint, such as: solvent (water), thickener, coalescent, dispersing agent, antifoaming agent, extender, anticorrosion agent, and different kinds of color pigments for the visual camouflage" and that these additives seem to increase the emissivity of a paint by about $10 \% .{ }^{10}$ Hedborg Karlsson et al. point out that the infrared reflectance is higher for the paint than for its individual components. ${ }^{42}$ The authors also considered the adhesion of their paint to be insufficient. The best combination of visible and TIR properties is reported by Shen et al. using a relatively complex $\mathrm{Al}$ based flake pigment. They are coated with $\mathrm{SiO}_{2}$ in order to prevent them oxidizing, which would otherwise increase the pigment emissivity. The high visible reflectivity of $\mathrm{Al} / \mathrm{SiO}_{2}$ is reduced by depositing metal oxides, ferro-cyanide and pure metal on the surface. None of the studies, however, reports on all the characteristics considered of interest for spectral design coatings in this review.

Table 1. The three best performing paints identified in the survey compared to desired characteristics.

\begin{tabular}{|c|c|c|c|c|c|c|}
\hline Coating syst. & $R V I S-N I R$ & Gloss & $D o P$ & Emissivity & $R R$ & $\begin{array}{l}\text { Controllabil } \\
\text { ity }\end{array}$ \\
\hline Desired: & $\begin{array}{l}\mathrm{R}_{\mathrm{VIS}}<15, \\
\mathrm{R}_{\mathrm{NIR}(\mathrm{g} .)} 45-60, \\
\mathrm{R}_{\mathrm{NIR}(\mathrm{br} .)} 10-25, \\
\mathrm{R}_{\mathrm{NIR}(\mathrm{bl.})} 5-10 \%\end{array}$ & Low & Low & $0.4-0.6$ & $\begin{array}{l}\text { Non } \\
\text { destruct. } \\
\left(\text { low } R_{\mathrm{RR}}\right)\end{array}$ & $\begin{array}{l}\text { Switchable } \\
\text { in near real } \\
\text { time }\end{array}$ \\
\hline $\begin{array}{l}18 \mu \mathrm{m} \mathrm{Al}, \text { flake, in water } \\
\text { solvable polymethyle acrylate, } \\
(\text { Hallberg et al. 2005) }\end{array}$ & "Green" & N.R. & N.R. & $\begin{array}{l}\mathrm{E}_{\text {MWIR }} 0.4 \\
\mathrm{E}_{\mathrm{LWIR}} 0.5\end{array}$ & $\begin{array}{l}\mathrm{T}_{\mathrm{RR}(\mathrm{X})} \\
>70 \%\end{array}$ & $\begin{array}{l}\text { In design } \\
\text { phase }\end{array}$ \\
\hline $\begin{array}{l}\text { 10-20 Al, flake, in } \\
\text { PEDOT:PSS, (Hedborg } \\
\text { Karlsson et al. 2007) }\end{array}$ & $\mathrm{R}_{\mathrm{NIR}} 50-70 \%$ & N.R. & N.R. & $0.2-0.3$ & N.R. & $\begin{array}{l}\text { In design } \\
\text { phase }\end{array}$ \\
\hline $\begin{array}{l}\mathrm{Al} / \mathrm{SiO}_{2} / \mathrm{Fe}_{2} \mathrm{O}_{3} / \mathrm{FeO} \\
/ \mathrm{Fe}_{4}\left[\mathrm{Fe}(\mathrm{CN})_{6}\right]_{3} / \mathrm{Cr}_{2} \mathrm{O}_{3} / \mathrm{Cr}, \\
\text { coated flake, in Appretan }{ }^{\circledR} \\
\mathrm{N} 96101,(\text { Shen et al. 2012) }\end{array}$ & $\begin{array}{l}\mathrm{R}_{\mathrm{VIS}}<15 \\
\mathrm{R}_{\mathrm{NIR}(\mathrm{g} .)} 55 \% \\
(0.38 \sim 1.2 \mu \mathrm{m})\end{array}$ & N.R. & N.R. & $\begin{array}{l}E_{\text {LWIR }} \\
0.51-0.55\end{array}$ & N.R. & $\begin{array}{l}\text { In design } \\
\text { phase }\end{array}$ \\
\hline
\end{tabular}

$$
\text { N.R. }=\text { Not reported }
$$

Summing up, the paint coating system remains an important area for research. There is currently an interest in multispectral aspects, such as: advanced pigments for low emissivity and selective properties in VIS-NIR, binders with little absorption in MWIR and LWIR and printing techniques for textiles.

\subsection{One-dimensional structures}

Moving from paints with pigments to coatings with layers of deposited optical films, we find other techniques and applications. Results from research in solar energy applications are assessed to be of particular interest since many of the challenges in techniques and processing are the same as in signature management, and even some of the desired characteristics in coatings are similar.

C.G. Granqvist sorts spectrally selective coatings into four categories: Low heat transfer (high $\mathrm{T} / \mathrm{A}_{\mathrm{VIS}+\mathrm{NIR}}$, high $\mathrm{R}_{\mathrm{TIR}}$ ); Solar control (high $\mathrm{T}_{\mathrm{VIS}}$, high $\mathrm{R}_{\mathrm{NIR}+\mathrm{TIR}}$ ); Smart Windows (Adaptable $\mathrm{R} / \mathrm{T}$ ) and Passive cooling (Low $\mathrm{R}_{\mathrm{TIR}}$ ). ${ }^{44}$ From the respective design criteria we find the second and third categories of primary interest in this study. 
Multilayer interference coatings for solar control are traditionally based on thin semi-transparent noble metal films deposited on glass substrates, embedded between oxide films of high refractive indices for antireflection and atmospheric protection purposes. ${ }^{45}$ Durability is known to be a problem. Exchanging the metal film for metal nitrides, such as TiN or $\mathrm{ZrN}$, is an option studied by Andersson et al. A $\mathrm{R}_{\mathrm{VIS}}$ of $<20 \%$, a $\mathrm{R}_{\mathrm{NIR}} 20-70 \%$ was reported. ${ }^{46,47}$ From reported data the emissivity is assessed to be in the 0.2-0.4 range. The films are specular and the polarization and radar-transmission are not known. Hallberg et al. have, however, demonstrated a possible method of exploiting the properties of multilayer coatings in signature management applications, despite the gloss, by removing the coating from the substrate and breaking it up into pigments. ${ }^{10}$ However, the high $\mathrm{R}_{\mathrm{NIR}}$ of the Au-pigment could not be achieved in the resulting paint. Nevertheless, pending the reasons for insufficient performance in the paint formulated by Hallberg et al. it would be interesting to investigate other highly IR-reflective, more stable, multilayer coatings used as pigments.

Efforts to achieve adaptable signatures in near real time make electro-chromic (EC) switching especially interesting since this phenomenon makes the optical performance of a surface controllable by using an electric signal. TC-coatings are undoubtedly of interest for spectral design purposes in heat control. Chemical switching ${ }^{48}$ and other switching phenomena could of course add to the knowledge of switching mechanisms for controllability, but have to be omitted from this survey because of a lack of space. In a paper on recent advances in chromogenics in $2009^{49}$ Granqvist et al report on EC-coatings for fenestration applications with considerable controllable transmittance intervals. They present a short overview of designing EC devices for fenestration purposes, consolidated in Table 2 below. Their latest results concern a polyester (PET) foil device, indicated in bold. The substrates were sputter coated and the final device was $0.4 \mathrm{~mm}$ thick and flexible. The mid-luminous transmittance, $\Delta \mathrm{T}$, is reported to be $55 \%$ with maximum transmittance around $70 \%$, and the time from colored to bleached state is about $30 \mathrm{~s}$. For this paper it is interesting to note that $\mathrm{R}_{\mathrm{VIS}}$ switches between 8 and approximately $15 \%$. $\mathrm{R}_{\mathrm{NIR}}$ is $30 \%$ at its maximum at around $2 \mu \mathrm{m}$. In a later review ${ }^{50}$ Granqvist reports on different EC-designs commercially available, with pros and cons, indicating that EC-switching technology has become mature for solar energy applications. A few years earlier some challenges in producing high quality devices on a large scale were reported. ${ }^{49}$

Table 2. An overview of designs for EC fenestration devices, based on advances reported by Granqvist et al 2009 (Their own latest device in bold).

\begin{tabular}{|c|c|c|}
\hline $\begin{array}{l}\text { Layer } \\
\#\end{array}$ & Function & Alternatives for fenestration ${ }^{49}$ \\
\hline 1 & Substrate & Flexible Polyester (PET) foil, Glass \\
\hline 2 & $\begin{array}{l}\text { Transparent } \\
\text { conductor, electrode }\end{array}$ & $\begin{array}{l}\mathbf{I n}_{2} \mathbf{O}_{3}: \text { Sn (i.e. ITO), heavily doped oxide semiconductors such as } \mathrm{ZnO}: \mathrm{Al}, \mathrm{ZnO}: \mathrm{Ga} \text {, or } \\
\mathrm{SnO}_{2}: \text { F. And possibly Metal-based coatings, carbon nanotubes or graphene }\end{array}$ \\
\hline 3 & Ion Storage layer/EC & $\begin{array}{l}\text { "Many", but } \mathrm{IrO}_{2} \text { and } \mathrm{NiO} \text { are of recent interest. } \mathrm{IrO} 2 \text { is expensive but has good EC- } \\
\text { properties after dilution with cheaper } \mathrm{Ta}_{2} \mathrm{O}_{5} \text {. NiO-based films mixed with wide band gap } \\
\text { oxides, such as } \mathrm{MgO} \text { or } \mathrm{Al}_{2} \mathrm{O}_{3} \text {, is an option. }\end{array}$ \\
\hline 4 & $\begin{array}{l}\text { Ion conducting } \\
\text { electrolyte }\end{array}$ & $\begin{array}{l}\text { "Many", including polymers with ion conduction due to added salts, ionic liquids, and } \\
\text { hydrous oxides exhibiting proton conduction }\end{array}$ \\
\hline 5 & $\begin{array}{l}\text { Electro Chromic } \\
\text { layer }(\mathrm{EC})\end{array}$ & $\mathrm{WO}_{3}$ \\
\hline 6 & $\begin{array}{l}\text { Transparent } \\
\text { conductor, electrode }\end{array}$ & See layer 2 \\
\hline 7 & Substrate & See layer 1 \\
\hline
\end{tabular}

Chandrasekhar et al. ${ }^{51-53}$, and others ${ }^{54}$, have presented different EC-devices with performance of interest to signature management in IR and for heat control of spacecraft. Using various parameters Chandrasekhar et al. demonstrate how their EC-devices can be tailored for optimized performance in specifically the MWIR and LWIR windows. ${ }^{51}$ "This is seen in practical Conducting Polymer devices in the form of thin $(<0.5 \mathrm{~mm})$, flexible, entirely solid-state, variable area 
$\left(1 \mathrm{~cm}^{2}\right.$ to $\left.1 \mathrm{~m}^{2}\right)$ flat panels. Typical properties include: very high reflectance variation; switching times $<2$ s. ${ }^{, 55}$ The MWIR emissivity can be varied between approximately 0.55 and 0.8 and the LWIR emissivity can be varied between approximately 0.3 and 0.85 .

The reflectance phenomena exploited in the materials presented so far have originated from boundaries. There are, however, some materials with lattice resonances, phonons, in the infrared part of the spectrum caused by light interacting with ion-pair dipoles. These quasi-particles are called Polaritons to separate them from ordinary lattice vibrations and hence the materials are called polar materials. To conclude, this is a bulk phenomenon and the optical consequence is an interval of high reflectance. In the literature this interval is known as the Reststrahlen band or the Polaritonic bandgap ${ }^{56}$. Sigalas et al. studied GaAs, but there are many materials exhibiting reststrahlen bands (see, for example, the Handbook of Optics ${ }^{57}$ ), though not that many in that part of IR of interest.

Beryllium Oxide $(\mathrm{BeO})$ and Boron Nitride $(\mathrm{BN})$ are two examples. They have reststrahlen bands resulting in high reflectance in the $9.5-15 \mu \mathrm{m}$ and the $8-9.5 \mu \mathrm{m}$ regions respectively. Ribbing showed in 1993 that a $2.5 \mu \mathrm{m}$ layer of $\mathrm{BeO}$ on BN could result in a coating with low emissivity, lower than 0.2 on average, covering the width of the LWIR atmospheric window ${ }^{58}$. Later the use of $\mathrm{BeO}$ in radar domes was suggested. ${ }^{59}$ This use would exploit the low emissivity, the off-band high emissivity and the excellent heat conducting properties - to reduce the probability of detection from IR sensors - combined with the electrical insulating properties allowing radar transmittance. The reflectance is diffuse and in the $80 \%$ range.${ }^{59}$ Since the safe deposition of a thin film of $\mathrm{BeO}$ on a substrate "is not a trivial problem" ${ }^{\text {, }}$, Ribbing et al. also suggest an alternative solution. A $0.83 \mu \mathrm{m}$ thin layer of Silicon is reported as being deposited on $\mathrm{BeO}$ in order to maximize the reflectivity on the short wavelength side of the low emissivity band. The resulting emittance is reported to be $0.1 .^{59}$

Högström et al. ${ }^{60,61}$ have also studied the coexistence of polaritonic and structure bandgaps in a multi-layer $\mathrm{Si} / \mathrm{SiO}_{2}$ onedimensional photonic crystal produced using Chemical Vapor Deposition. Silicon was used as a high index dielectric and $\mathrm{SiO}_{2}$ was used as a low index dielectric. In addition $\mathrm{SiO}_{2}$ has a reststrahlen band in the 8-9.3 $\mu \mathrm{m}$ wavelength range. It was shown that the two bandgap phenomena can be combined and that the polaritonic gap can either be strengthened or made to vanish by choice of periodic structure. ${ }^{47}$ It is even possible to combine the two materials in a coating design to give low emittance in both atmospheric windows, 0.24 in MWIR and 0.38 in TIR, exploiting the structure gap for the former and the polaritonic gap for the latter. ${ }^{58}$ In between the windows the emissivity is mostly above 0.7 . The polaritonic gap reflectance is reported to be robust, while the structure gap reflectance is sensitive to angle of incidence. The structure reflectance moves to shorter wavelengths and the polaritonic reflectance widens with angle of incidence. ${ }^{62}$

Lately rather complex structured bandgap materials have been reported. Zhao et al. report on the possible performance of a one-dimensional, two defect modes, photonic crystal based on principles of Distributed Bragg Reflector microcavity ${ }^{\dagger \dagger}$. The structure was modeled with the MWIR and LWIR-transparent materials, $\mathrm{PbTe}$ and $\mathrm{Na}_{3} \mathrm{AlF}_{6}$, as high refractive index and low refractive index materials respectively. This way it is possible to obtain a photon inhibiting, highly reflective, band cross the $1-20 \mu \mathrm{m}$ spectrum. At the same time, at $1.06 \mu \mathrm{m}$ and $10.6 \mu \mathrm{m}$, the two microcavities cause spectral transmittance greater than $96 \%$, i.e. at military laser wavelengths. The authors conclude that this performance will satisfy laser and infrared stealth in NIR, MWIR and LWIR. ${ }^{63}$ The material is far from being put to use, but the results show the potential in this line of development.

Ribbing, however, explains that some promising results have been accomplished using photonic crystal as a component in a Multi-Spectral Camouflage Coating (MSCC) for ground applications as well as for aircraft applications $\$$. Nordin

\footnotetext{
${ }^{\dagger}$ Defects in the periodic structure designed to be resonators at a very specific wavelength

㭋 Personal communication, Professor Carl-Gustaf Ribbing, June 2014
} 
reported on this at a Swedish seminar on signature management in $2012 .{ }^{64 \S}$ MSCC is a $2 \mathrm{~mm}$ thick rubber-like decal in three layers, supplied by the meter. The bottom layer is for radar absorption, the middle layer is for IR and the topmost layer is for VIS and NIR. Decals of the MSCC are cut from the roll and glued directly to the surface of the platform. The presentation did not include performance details other than that the IR layer design is based on photonic crystal and that it has proved to be transparent for radar wavelengths. Results from characterization would be interesting.

Summing up, one-dimensional structures, i.e. multilayer coatings, have at least three directions of development. Multilayer interference coatings are used to tailor bands of maximum reflectance or transmittance, and hence is one approach to better low emissive pigments. Another direction of development is so called bandgap materials, either natural polaritonic materials, or (periodic) structured bandgap materials. Their advantage is having bands of reflectance without being electrically conductive. However, it is still not clear how to apply them in a coating system. If applied as a decal they risk having a strongly angular dependent reflectance. A third direction of development is flexible and controllable electro-chromic devices utilizing conducting polymers, potentially applied as decals on military platforms. One-dimensional structures, however, run the risk of being glossy.

\subsection{Multidimensional structures}

In 1987 Yablonovitch and John published papers on how to control electromagnetic wave propagation in man-made periodic structures of dielectric media, later called Photonic Crystals (PhC). It was shown that, under certain structural symmetry conditions and a large enough ratio between refractive indices of the constituent dielectric materials, an energy band gap appears. The term (optical) band gap is used in analogy with electronic band gaps. ${ }^{65,66}$ There may be gaps in the energy band structure of the crystal, meaning that electrons are prevented from propagating with certain energies in certain directions. If the lattice potential is strong enough, the gap can extend to cover all possible propagation directions, resulting in a complete band gap. The optical analogue is the $\mathrm{PhC}$, in which the atoms or molecules are replaced by macroscopic media with differing dielectric constants, and the periodic potential is replaced by a periodic dielectric function. If the dielectric constants of the materials in the crystal are sufficiently different, and if the absorption of light by the materials is minimal, then the refractions and reflections of light from all of the various interfaces can produce many of the same phenomena for photons (light modes) that the atomic potential produces for electrons. ${ }^{67}$ The optical consequences are suppression of emission in the crystal and total reflectance of light in a wavelength region determined by the lattice constant of the structure and with a broadening corresponding to the band gap. One might also note that the preconditions for constructive interference in multilayer interference coatings and reflectance bands from photonic crystals show strong analogy. This would be why interference coatings are sometimes also called one-dimensional photonic crystals or structured band gap materials. Thus, a naïve approach to the theory of 3D photonic crystals would be to view them as a "3D interference" phenomenon. To conclude, the potential in 3D photonic crystals for spectral design is twofold. Firstly, to limit the angular dependence of emission, and secondly, the possibility of tailoring the spectral width and position of reflectance and transmittance bands using easy-to-come-by-and-process materials simply by tuning structure and symmetry.

PhCs discussed at the beginning of the section are compounds of dielectrics. As early as 1996, though, Sigalas et al. pointed out features using metals. The materials would be much smaller in size and weight than the all dielectric photonic band gap materials, but would be absorbent. ${ }^{68}$ There is a continued interest in metallic PhCs and some reported applications in spectral design. ${ }^{69,70}$

During the last half of the 1990s the manufacture and characterization of 3D PhCs developed from being possible at millimeter wavelengths to NIR. ${ }^{71-73}$ In 2006 Aliev et al. reported the successful fabrication of large surface areas of 3D PhCs optimized for high reflectivity in the MWIR and LWIR bands. The process involved self-assembling large $\mathrm{SiO}_{2}$

$\S \S$ http://www.yki.se/en/media/news/Sidor/090831.aspx, 20/08/2014 
spheres, of $0.8-4.5 \mu \mathrm{m}$ diameters, followed by melt infiltration with chalcogenide glass $\mathrm{Ge}_{33} \mathrm{As}_{12} \mathrm{Se}_{55}$ and removal of the $\mathrm{SiO}_{2}$ spheres by chemical etching. ${ }^{74}$ The title of the paper indicates fabrication of pigments, but this part of the process is not described. Characterization of a paint coating system with this kind of synthetic pigment would be very interesting, but to our knowledge nothing has been reported.

Today, when doing literature search for PhCs, there is a vast amount of matching and very recent references, most with applications such as PhC-fibers, optical waveguides, components in efficient lasers and other. There are, however, a few authors reporting research into multispectral SMT. Albertoni et al. simulate a set of PhC structures and show the possibility of managing the flow of LWIR light around a target and how to control it in order to make a thermal photonic camouflage device. "The $\mathrm{PhC}$ is able to collect thermal light from the environment and transport it virtually on every point of the devices". The authors state that these devices can be designed to change the reflection angle in order to camouflage the spatial signature of the target. ${ }^{75,76}$ Kadiyala et al. demonstrate, through optical modeling of polymerized colloidal crystalline array (PCCA) structures, a novel concept that has the potential to enable the use of tunable 3D photonic crystals for adaptive camouflage. The phenomenon used for tuning is photo-responsive isomerization. The wavelength shift reported using a diamond lattice structure of spheres surrounded with azobenzene polymer is only a few nanometers. The authors state, however, that they will continue to optimize the model by varying different lattice parameters and material properties and that "the ultimate result of all such optimizations is to achieve an all angle adaptive camouflage coating". ${ }^{77}$

To summarize, there is extensive research on photonic crystals and the research for spectral design purposes could benefit. 3D PhC pigments have been realized using seemingly cost effective fabrication techniques, but the application in paint coating systems remains to be seen. There are results reported indicating that continued research on PhCs turns into research on Metamaterials (see next section) and advanced management of light rays.

\subsection{Biomimic and Metamaterials}

Environmental friendly non-fading brilliant colors seen on the feathers of some birds, and on the wings of butterflies, are due to structures and are thus called Structural Colors. The phenomenon was first observed and described by Hooke in "Micrographia" in $1665 .{ }^{78}$ There has been a vast number of studies since on the optical properties of multilayers in fish scales, on photonic structures in butterfly wings and on the iridescence from golden beetles etc., describing the structural colors, the photonic crystals and other optical surface properties in nature. ${ }^{79-86}$

Structural coloration is based on the reflection of light while pigment coloration is a result of absorption. Structural colors can be both iridescent, when the color changes with viewing angle (interference or diffraction phenomena), and non-iridescent, when the color originates from scattering and structural irregularities. Sun et.al. have produced an excellent review of the different kinds of colors structures, and have also described attempts at mimicking. ${ }^{87}$ The coloration of mimicked structures will, as in the natural case, arise through common physical mechanisms such as thin film or multilayer interference, diffraction gratings, scattering (coherent and incoherent) and photonic crystals etc., depending on the composition of the building blocks.

Biomimetics, introduced by Schmitt in $1957^{88}$, is the art of mimicking structures, found in nature, to improve functionality in artificial devices and to find inspiration for novel applications. ${ }^{89,90}$ One example is butterfly wings. They have been used as a template for preparing replicas in the form of large area periodic $\mathrm{ZrO}_{2}$ structures for potential applications and integration in optical technology. ${ }^{91}$ Another example is the reflective scales on the wings of the butterfly Argyrophorus argenteus, which have broadband reflecting properties. Scaled-up replicas with thicknesses $<1 \mu \mathrm{m}$ have been manufactured and investigated using microwaves. ${ }^{92}$ It has been suggested that the structures of cicada wings have a camouflage-like anti-reflection function ${ }^{93}$ and inorganic replicas of these structures, for use in solar cell applications, are now emerging. ${ }^{94}$ 
Tailored reflectance is desirable in SMT. Fractals as a concept was first introduced by Mandelbrot in the 1970s. ${ }^{95}$ A fractal is a fragmented geometric shape that is self-similar, i.e. when several parts shaped alike are put together, the new larger shape, looks like one of the smaller shapes. Fractal structures often have properties between random and ordered structures and can be of interest in obtaining broadband reflectance. Examples of structures closely resembling fractal structures are found in nature, these could include mountain ranges, river networks, coastlines, snowflakes, blood vessel systems and broccoli.

Polarization is another important characteristic in SMT. Polarization is in fact important for the sight of birds and insects; the dung beetle needs to sense polarization for orientation, ${ }^{96}$ and there have been some studies of reflected light from the cuticles of beetles. ${ }^{97-99}$ Polarization properties vary between: specular reflection, polarizing light circularly, strong scattering of linear polarized light, preserving polarization and having depolarizing properties. ${ }^{99}$ Attempts to mimic polarization effects have also been exemplified by Sun et.al. ${ }^{87}$

Controllability is yet another example of desirable features in SMT and several examples of dynamic colors exist in nature, for example in insects or squids. A color change can be caused by a variation in the photonic structure, in the angle of incident light, in index of refraction contrast, or other environmental stimuli such as humidity or temperature. Attempts to mimic are exemplified by Sun et.al. ${ }^{87}$

In biology structures with double functionalities are common. One example is the combination of an optical characteristic and water repelling function, such as the anti-reflective eyes of a moth. Inspired by this, Askar et.al have shown how the hydrophobicity of a substrate surface can be enhanced and self-cleaning AR coatings developed, using structures of nanopillars with high aspect ratio properties. These coatings can be useful in improving conversion efficiency and reducing glare in optical devices. ${ }^{100}$

In biology simple materials are used. The most abundant and complex structures found in nature, chitin, cellulose and chlorophyll, are built from combinations of carbon, oxygen and hydrogen. The microstructure of chitin, for example, is, however, the origin for iridescent colors of butterflies and insects, which in turn have inspired the development of future photonic structure materials. ${ }^{10194102}$ In the laboratory environment, on the other hand, very complex materials are created, but often in very simple structures. Nevertheless, with the development in nanotechnology and manufacturing, and with inspiration from nature, future combinations of complex materials and advanced structures are assessed to have great potential - for example, in spectral design for SMT.

Two examples are chosen to show the potential in nano-composites for camouflage. Chun et al. deposit a nanocomposite coating of Ni-P-CB on an ABS plastic matrix and show that it has low infrared emissivity. ${ }^{103}$ Wang shows how improved microwave absorption in a wide band, combined with low infrared emissivity, can be achieved by incorporating $\mathrm{TiO}_{2}$ or $\mathrm{Al}_{2} \mathrm{O}_{3}$ into an ordered mesoporous structure of carbon. Besides good impedance matching, the large surface area and tunable pore-size make it an interesting material for a vast range of applications. Wang et al. suggest using it for simultaneous microwave absorption and infrared camouflage. ${ }^{104,105}$

Metamaterials are often described as artificial structures appearing as a material at some frequency range, with properties that cannot be found in nature. The properties of metamaterials are gained from the structure instead of the material. Applications range from perfect or super-focusing lenses, antennas, all-optical memories and gradient-index materials to "invisibility" cloaking. Even though total invisibility is impossible, the reduction of both optical and acoustic visibility is important in general terms for signature reduction. However, today, optical metamaterials at visible wavelengths are extremely thin and rather glossy, which means the synthesis is rather challenging. ${ }^{106}$

To some extent military signature management and space applications are alike; functionality is needed in a harsh environment. Venancio et.al, have presented an excellent list of classification of metamaterial with promising properties for space applications, from surfaces with anti-reflection to absorbent properties, sub-diffraction imaging properties and 
materials with polarization control functions and lastly, spectral properties for filtering and for dichroic properties. They suggest further studies on following functionalities and metamaterials for space application: An absorber for stray-light baffling using low-density arrays of long nanotubes and polarization scrambling using either 1D meander structure or double mesh structures. ${ }^{107}$

An important part of research, in order to understand and concretize future advanced structures, such as multispectral camouflage, is modeling and simulation. A few examples of theoretical modeling of metamaterials deal with antireflection properties ${ }^{108}$, modification of radiation characteristics ${ }^{75}$, tunable photonic bandgaps for electromagnetic invisibility cloaks ${ }^{76}$ and high-absorption surfaces ${ }^{109}$. Thanks to improvements in micro and nano-technology some are even experimentally verified. Realization of large surface area lithographic methods, for example micro contact printing or nano-imprint, is enabled through the use of realistic geometrics for the structures, such as metallic cross grating or perforated plates. ${ }^{108}$ Chen has produced an excellent overview and has also theoretically and practically studied the feasibility and implementation of mantle cloaks for 1-3D objects. ${ }^{110} \mathrm{He}$ found them beneficial for invisibility and camouflage applications because they reduce the overall visibility.

Today limited bandwidth, losses and imperfections severely limit current metamaterial cloaks. A low profile of an ultrathin mantle cloak improves bandwidth limitations; however, little or nothing is said about the robustness to losses. Often theoretical simulations show promising results that are difficult to realize due to imperfections.

To summarize, functionality in nature is, to a large extent, based on complex structures and a lot can be mimicked to find new and effective or multifunctional design solutions, not least in spectral design. There is potential in being able to combine the complex structures of nature with the complex materials of material science. Great challenges remain to overcome problems regarding bandwidth and losses at short frequencies.

A final note, the categorization of materials and structure concepts used in this paper is not perfect, as there are materials and structures that might fit into several categories. There are trends also in materials and structures research it seems.

\section{SUMMARY AND CONCLUSIONS}

An overview of materials, surface structures and coating principles of potential interest for signature management applications using spectral design is presented. In order to limit the scope of the survey, the desired properties used as indicators were derived from optical multispectral camouflage, i.e. applications requiring low contrast with the background. The major trends and areas of development are covered, but a systematic review proved to be too ambitious for the space available in this paper, and some potentially interesting research areas, like for instance graphene or mimicking shape shifting surfaces from biology, have been left out.

The results are structured in order of increasing complexity, where challenges within one order of complexity could be regarded a driving force within the next. The starting point is developments in paint coating systems. It is regarded as the basic, traditional, technology for signature management since it is relatively easy to apply, protective properties can be built in and it is fairly cheap. The challenge is to combine pigments and binders in a system where the properties of the components create a synergetic optical response throughout the spectrum from VIS to TIR. Pigments and binders used for a narrower spectrum are absorbent (emissive) in thermal infrared and hence cannot meet an optically multispectral threat. The best coatings found are based on coated flake pigments of aluminum. Adhesion, high reflectivity in the visible spectrum and a tendency to form electrically conductive coatings, which disturb the radar signature, are remaining challenges.

Here multilayered structures are regarded as the second order of complexity. Breaking metal based multilayers into pigments is one approach to tailoring the reflectivity, but no paint coating system reported yet meets the potential of the respective components. Another approach is using non-conducting bandgap materials in layers, either naturally 
polaritonic materials, structured bandgap materials (also called one-dimensional photonic crystals) or a combination thereof. Using multi-layered structures it is possible to create electro-chromic coatings, making the transmittance controllable to a certain extent across interesting optical wavelengths. This latter technique is assessed to have potential through the use of suitably pixel-sized decals on military platforms, maybe in combination with other coating systems. One foreseeable challenge is gloss.

The optical response of any one-dimensional structure is, however, bound to be dependent on the angle of incidence of irradiating light, which is why there is great interest in the development of structured bandgap materials in three dimensions, so called 3D photonic crystals. The advantage expected is not being dependent on rare properties of specific materials, but instead being able to tailor reflectance bands by tuning the size of a periodic structure, using suitable materials easier to obtain or process. Photonic crystals for infrared wavelengths have been reported, but there are no reports yet, to our knowledge, on the characterization of a coating system for signature management.

Our fourth order of complexity is biomimic and metamaterials. To learn more about the properties of complex structures many researchers are now turning to biology. In biology there are examples of interesting optical properties, such as ageresistant and environmentally friendly colors, originating from complex structures made out of relatively simple materials. Laboratories report advanced material combinations, albeit in relatively simple structures. Consequently, there is potential in combining advanced materials with complex structures from nature, and developments in nano-technology show great promise. Hopefully it will be possible to combine properties and satisfy military requirements for surfaces other than the optical response, such as dirt resistance, thereby increasing the military utility of spectral design.

None of the reports found have studied all six of the desired characteristics of a multispectral optical coating for signature management. Gloss is sometimes mentioned indirectly, but without being quantified. Often only the specular or integrated reflectance is reported. In research on biomimetics and metamaterials there are reports on polarization properties, but only, it seems, because the application is related to antennas. Characterization of optical coatings in the radar wavelength range was only found in one report. Either, there is still a lack of interest in studying multispectral properties, or the correct nomenclature was not used when probing for results, or these areas are classified. There is, however, a great interest in low emissive coatings in the civilian energy sector or, militarily, for heat control or space applications. Most coatings are assessed only to have controllability when designed, and could be used for static signature systems. Controllability for near real-time applications may be obtained using electro-chromic devices based on conducting polymers, or further in the future using tunable 3D photonic crystal.

In summary there are no ready-made solutions to optically multispectral, spectral design coatings for signature management. There are, however, promising ideas about how to move forward, which is why spectral design is assessed to have continued great potential. The utility of spectral design is also assessed to benefit from research into other applications and from commercial interest in nano-technology, boosted, for example, by the electronics, construction and energy industries.

\section{FUTURE WORK}

Based on the conclusions of the results reported, there is obviously great interest in continuing research into advanced materials and structures, and their characterization. There are, however, few results reported on applied spectral design coatings for signature management. It would be interesting, from a military utility point of view, to learn more about how the different approaches to spectral design could be combined in applied coatings - and what properties these structures could have. A first step must be learning more about how to model the optical behavior of such a compound coating system, with multiple materials in complex structures - both in order to be able to design usable coatings meeting functional requirements, and to put relevant functional requirements on spectral design. 
This also highlights a second research area of great interest. What are the requirements of military coatings applied to platforms, uniforms or other systems? Without specific requirements the true military utility of spectral design, the performance achieved by coatings, and related research, cannot be assessed. Therefore, in order to spend limited military $R \& D$ funding more effectively, and to meet more quickly the survivability requirements of signature management systems from an increased threat, there is a need to study the balancing process depicted in the introduction. There is a need to understand or develop the process of how to assess the military utility of advances in spectral design, and in the other direction, how to get from desired military utility to the relevant requirements of spectral design. The work presented here forms one end of the process and recent work ${ }^{111}$ on the concept of military utility forms the other. Using this concept the military utility of signature management applied to a system, e.g. a combat vehicle, is considered to be a compound measurement of its military effectiveness, its suitability to the military capability system concerned, and its affordability.

\section{AKNOWLEDGEMENTS}

This work was financially supported by the Swedish National Defence College and the Swedish Armed Forces. The authors would also like to thank Dr Hans Kariis, Dr Steven Savage, Dr Thomas Hallberg, Professor C-G Ribbing (emeritus), Professor Gunnar Hult and the signature materials project group at the Swedish Defence Research Agency for valuable input.

\section{REFERENCES}

All FOI-reports are available at http://www.foi.se/en/Search/

[1] Swedish Department of Defence, "Försvaret av Sverige Starkare försvar för en osäker tid", 151 (2014). www.regeringen.se/content/1/c6/24/04/14/263c8454.pdf. (24 August 2014)

[2] Bohman, L., "Sensorer mot markmål", FOI-R--3476--SE, Linköping, 67 (2012)

[3] Bohman, L. (ed), [Handbook on signature management technology for ground], FOI, (2003).

[4] Kariis, H, Björkert, S, Forssell, G, et al. "Styrbara signaturmaterial - möjligheter och forskningsbehov", FOI-R--1412-SE , 34 (2004).

[5] Olsson, Ö., Karlsson, L., Lindwall, P., Dickman, O., Grop, A., "A Systems Approach to Stealth on Ground ; SAT/Mark Technology Demonstrator", SPIE Proc. 4718, 1-11 (2002).

[6] Arwin, H., [Thin Film Optics and Polarized Light], University of Linköping, Linköping, 372 (2014)

[7] Bergström, D, Sjöqvist, L, Gustafsson, D., "Passive and active spectropolarimetric imaging for target detection - a literature review study", FOI, 139 (2012).

[8] Jacobs, P. A., [Thermal Infrared Characterization of Ground Targets and Backgrounds], SPIE, 184 (2006).

[9] Driggers, R. G., Friedman, M. H., Nichols, J. M., [Introduction to Infrared and Electrooptical systems], Artech House, Boston \& London, 583 (2012).

[10] Hallberg, T., Niinimäki-heikkilä, T., Hedborg-Karlsson, E., Salonen, P. S., Nilsson, C., Jänis, A. "Development of lowemissive camouflage paint : Final report Development of low-emissive camouflage paint : Final report", FOI, (2005)

[11] Rubežien, V., Baltušnikait, J., Padleckien, I., "Development of Visible and Near Infrared Camouflage Textile Materials", Materials Science (Medžiagotyra), 15(2), 1-5, (2009).

[12] Rubeziene, V., Padleckiene, I., Baltusnikaite, J., Varnaite, S., "Evaluation of Camouflage Effectiveness of Printed Fabrics in Visible and Near Infrared Radiation Spectral Ranges", Mater Sci., 14(4), 361-365, (2008).

[13] Åkerlind, C., Jänis, A., Kariis, H., Arwin, H., Järrendahl, K., "Spectroscopic ellipsometry and vector network analysis for determination of the electromagnetic response in two wavelength regions", Phys Status Solidi., 5(5), 1089-1092 (2008).

[14] Kariis, H., Andersson, Å., Hallberg, T. Pohl, A., Savage, S., "Signaturanpassning, soldat - utvecklingen inom signaturmaterial 2012", FOI-R--3558--SE (2013).

[15] Wake, L.V., Brady, R.F., "Formulating Infrared Coatings for Defence Applications", DSTO Report (1993). www.dtic.mil/dtic/tr/fulltext/u2/a267555.pdf

[16] Sward, G. G., Jacobsen, A. E., "Paint Testing Manual", 13th ed., A. Soc. Test. Mater., Philadelphia, PA (1972). 
[17] Hedborg Karlsson, E., Hallberg, T., "Optiska egenskaper hos metallbelagda cenosfärer", FOI-R--0878--SE (2003).

[18] Hedborg Karlsson, E., Nilsson, C., Hallberg, T., Kariis, H., "Technical report Pigments with Potential for Adaptable Optical Properties", FOI-R--1256--SE (2004).

[19] Thongkanluang, T., Limsuwan, P., Rakkwamsuk, P., "Preparation and Application of High Near-Infrared Reflective Green Pigment for Ceramic Tile Roofs", Int J Appl Ceram Technol., 8(6), 1451-1458 (2011).

[20] Sarasamma Vishnu, V., Lakshmipathi Reddy, M., "Near-infrared reflecting inorganic pigments based on molybdenum and praseodymium doped yttrium cerate: Synthesis, characterization and optical properties", Sol Energy Mater Sol Cells, 95(9), 2685-2692 (2011).

[21] Wang, J-L., Li, Y-Q., Byon, Y-J., Mei, S-G., Zhang, G-L., "Synthesis and characterization of NiTiO3 yellow nano pigment with high solar radiation reflection efficiency", Powder Technol. 235, 303-306 (2013).

[22] Ferrari, C., Libbra, A., Mucio, A., Siligardi, C., "Design of ceramic tiles with high solar reflectance through the development of a functional engobe", 39, 9583-9590 (2013).

[23] Anon, "Huntsman launches infrared reflecting pigments", Addit Polym., 7, 2-3 (2012).

[24] Jose, S., Reddy, M. L., "Lanthanum-strontium copper silicates as intense blue inorganic pigments with high nearinfrared reflectance. Dye Pigment", Dyes and Pigments, 98(3), 540-546 (2013).

[25] Ramsley, A.O., Bushnell, W.B., "Development of the U.S. woodland battle dress uniform", US Army Natick/TR81/008, (1981).

[26] Baltušnikait, J., Padleckien, I., "Development of Visible and Near Infrared Camouflage Textile Materials", Materials Science (Medžiagotyra), 15(2), 1-5 (2009).

[27] Gupta, K. K., Nishkam, A., Kasturiya, N., "Camouflage in the Non-visible Region", Journal of Industrial Textiles, 31(1), 27-42 (2001).

[28] Clarkson, G. M., "Camouflage fabric", US Patent no 5798304, (1998).

[29] Coleman, R. A., "Application of Infrared Absorbers to Nylon 6,6", US Army Natick Laboratories TR-75-19 (1974).

[30] Holcombe, J.D., Nandi, M. K., "Infrared Suppressive Material", US Patent no 20070009679 (2007).

[31] Sioen, J.J., Wille, J., "Infrared Shielding and Radar Attenuating Textile Material", European Pat. EP 1703 247 A1, 1-13 (2006).

[32] Frankel, K., Sousa, S., Cowan, R., King, M., Concealment Of The Warfighter's Equipment Through Enhanced Polymer Technology", U.S. Army Natick Soldier Center Natick (2004).

http://oai.dtic.mil/oai/oai?verb=getRecord\&metadataPrefix=html\&identifier=ADA433437

[33] Kariis, H., Andersson, Å., Hallberg, T., Pohl, A., Savage, S., "Signaturanpassning soldat. Utvecklingen inom signaturmaterial 2012", FOI-R--3558--SE (2013).

[34] Zhang, H., Zhang, J. C., "Near-infrared green camouflage of cotton fabrics using vat dyes", J Text. Inst., 99(1), 83-88 (2008).

[35] Mao, Z., Yu, X., Zhang, L., Zhong, Y., Xu, H., "Novel infrared stealth property of cotton fabrics coated with nano ZnO: (Al, La) particles", Vacuum, 104, 111-115 (2014).

[36] Mao, Z., Wang, W., Liu, Y., Zhang, L., Xu, H., Zhong, Y., "Infrared stealth property based on semiconductor ( M ) -tometallic ( R ) phase transition characteristics of W-doped VO 2 thin films coated on cotton fabrics", Vacuum, 558, 208214 (2014).

[37] Qian, G., Wang, Z.Y., "Near-Infrared Thermochromic Diazapentalene Dyes", Advanced Materials, 1582-1588 (2012).

[38] McCann, "No Title", Surf Coatings Aust. 27(8), (1990).

[39] Mar, H. Y. B., Zimmer, P. B., "Low infrared emissivity paints comprising an Oxime cured Silicone binder", US Patent 4131593, 2-5 (1978).

[40] Brady, R. F. "The Chemistry Of Film-Forming Resins", J Prot Coatings Linings, 4(7) (1987).

[41] Lee, H-S., Staaf, Ö., Ghaem, H., "IR-properties of some binders for the coatings industry", FOA-R--00-01576-615 (2000).

[42] Hedborg Karlsson, E., Kariis, H., Andersson, Å., Åkerlind, C., "Ny typ av lågemissiv kamouflagefärg - slutrapport", FOI-R--2316--SE (2007).

[43] Shen, F.C., Feng, X. X., Ma, T., Zhang, J. C., Zhang, H., Gao, P. G., "Study on the Low-Emissive Camouflage Pigment", Adv Mater Res., 624, 303-306 (2012).

[44] Granqvist, C. G., "Solar Energy Material", Appl Phys. 52, 83-93 (1991).

[45] Fan, J. C. C., Bachner, F. J., Fole, G. H., Zavracky, P. M., "Transparent heat-mirror films of TiO2/Ag/TiO2 for solar energy collection and radiation insulation", Appl Phys Lett., 25(12), 693 (1974). 
[46] Andersson, K. E., Veszelei, M., Roos, A., "Zirconium nitride based transparent heat mirror coatings — preparation and characterisation", "Sol Energy Mater Sol Cells, 32(2), 199-212 (1994).

[47] Andersson, K. E., Wahlström, M. K., Roos, A., "High stability titanium nitride based solar control films", Thin Solid Films, 214(2):213-218 (1992).

[48] Åkerlind, C., Arwin, H., Jakobsson, F. L. E., Kariis, H., Järrendahl, K., "Optical properties and switching of a Rose Bengal derivative: A spectroscopic ellipsometry study", Thin Solid Films 519, 3582-3586 (2011).

[49] Granqvist, C. G., Lansåker, P. C., Mlyuka, N. R., Niklasson, G., Avendaño, E., "Progress in chromogenics: New results for electrochromic and thermochromic materials and devices", Sol Energy Mater Sol Cells, 93(12), 2032-2039 (2009).

[50] Granqvist, C. G., "Solar Energy Materials \& Solar Cells Oxide electrochromics: An introduction to devices and materials", 99, 1-13 (2012).

[51] Chandrasekhar, P., Zay, B. J., Mcqueeney, T., Birur, G. C., Sitaram, V., "Physical, chemical , theoretical aspects of conducting polymer electrochromics in the visible , IR and microwave regions", Synth Met., 155, 623-627 (2005).

[52] Chandrasekhar, Zay, McQueeney, et al., "Conducting Polymer (CP) infrared electrochromics in spacecraft thermal control and military applications", Synth Met., 136, 23-24 (2003).

[53] Chandrasekhar, P., Zay, B., Ross, D., "Far-IR-through-visible electrochromics based on conducting polymers for spacecraft thermal control and military uses ...", In: Chromogenic Phenomena in Polymers, American Chemical Society, 66-79 (2005).

[54] Franke, E., Neumann, H., Schubert, M., Trimble, C. L., Yan, L., Woollam, J. A., "Low-orbit-environment protective coating for all-solid-state electrochromic surface heat radiation control devices", Surf Coatings Technol., 151-152, 285288, (2002).

[55] Chandrasekhar, P., Zay, B. J., Birur, G. C., et al., "Large, Switchable Electrochromism in the Visible Through FarInfrared in Conducting Polymer Devices", Adv Funct Mater., 12(2):95-103 (2002).

[56] Sigalas, M. M., Soukoulis, C., Chan, T., Ho, K. M., "Electromagnetic-wave propagation through dispersive and absorptive photonic-band-gap materials", Phys Rev B., 49(16) (1994).

[57] Dobrowolski, J., Driscoll, W., Vaughan S., [Coatings and Filters Handb Opt. ], ch. 8 sect. 99 (1978).

[58] Ribbing, C. G., "Reststrahlen material bilayers: an option for tailoring in the infrared", Appl Opt., 32(28), 5531-4 (1993).

[59] Ribbing, C. G., Staaf, Ö., Andersson, S. K., "Beryllium oxide - a material for selective supression of thermal emission from domes", SPIE Proc. 2286, 510-520 (1995)

[60] Högström, H., Ribbing, C. G., "Polaritonic and photonic gaps in SiO2/Si and SiO2/air periodic structures", Photonics and Nanostructures - Fundam Appl., 2(1), 23-32 (2004).

[61] Högström, H., Forssell, G., Ribbing, C. G., "Realization of selective low emittance in both thermal atmospheric windows", Opt Eng., 44(2) (2005).

[62] Högström, H., Ribbing, C. G., "On the angular dependence of gaps in 1-D Si/SiO2 periodic structures", Opt Commun. 271(1), 148-153 (2007).

[63] Zhao, X., Zhao, Q., Zhang, Q., Wang, L., "Numerical study on laser and infrared compatible stealth by forming "holedigging spectrum" of doped photonic crystal", Proc. of SPIE., Vol 7847 (2010).

[64] Nordin P., "MSCC, vägen framåt", Symposium i signaturanpassningsteknik, September 4-5, (2012).

[65] Yablonovitch, E., "Inhibited Spontaneous Emission in Solid-State Physics and Electronics", Physical review letters., 58(20), 2059-2062 (1987).

[66] John, S., "Strong Localization of Photons in Certain Disordered Dielectric Superlattices", Phys Rev Lett., 58(23), 24862489 (1987).

[67] Joannopoulos, J. D., Johnson, S. G., Winn, J. N., Meade, R. D., "Photonic Crystals", 2nd ed. Princeton University Press (2008).

[68] Sigalas, M. M., Chan, C. T., Ho, K. M., Soukoulis, C. M., "Metallic photonic band-gap materials", Phys Rev B., 52(16) (1995).

[69] Fleming, J. G., Lin, S. Y., El-Kady, I., Biswas, R., Ho, K. M., "All-metallic three-dimensional photonic crystals with a large infrared bandgap", Nature, 417, 52-55 (2002).

[70] Gao, H-C., Dai, S-T., "A novel material with low infrared target features", 27(4), 671-4 (2007). http://europepmc.org/abstract/MED/17608172

[71] Soukoulis, C. M., "Photonic Band Gap Materials: The "Semiconductors" of the future?", Phys Scr. T66, 146-150 (1996). 
[72] Lin, S., Fleming, J., Hetherington, D., et al., "A three-dimensional photonic crystal operating at infrared wavelengths", Nature, 394(6690), 251-253 (1998).

[73] Noda, S., "Full Three-Dimensional Photonic Bandgap Crystals at Near-Infrared Wavelengths", Scienc, 289(5479), 604606 (2000).

[74] Aliev, A. E., Zakhidov, A. A., Baughman R. H., Yablonovitch, E., "Chalcogenide Inverted Opal Photonic Crystal as Infrared Pigments", Int J Nanosci., 5(1), 157-172 (2006).

[75] Albertoni, A., Perfetto, S., "Mid wave and long wave infrared metamaterials and nano-materials design with Finite Element and Finite Difference Time Domain models for target camouflage", SPIE Proc. 7834, (2010).

[76] Albertoni, A., "Long wave infrared metamaterials and nano-materials design, simulation, and laboratory test for target camouflage in the defence application", SPIE Proc. 8185 (2011).

[77] Kadiyala. A., Dawson, J. M., Hornak, L. A., "Modeling of a 3-D Tunable Photonic Crystal for Camouflage Coating", SPIE Proc. 7781 (2010)

[78] Hooke, R., [Micrographia: or, Some physiological descriptions of minute bodies made by magnifying glasses], London, J. Martyn and J. Allestry (1665).

[79] Berthier, S., Charron, E., Boulenguez, J., "Morphological structure and optical properties of the wings of Morphidae", Insect Sci., 13(2), 145-158 (2006).

[80] Seago, A. E., Brady, P., Vigneron, J-P., Schultz, T. D., "Gold bugs and beyond: a review of iridescence and structural colour mechanisms in beetles (Coleoptera",. J R Soc Interface, 6 suppl 2, 165-84(2009)

[81] Vukusic, P., Sambles, J. R., "Photonic structures in biology", Nature, 424(6950), 852-5, (2003).

[82] Bradley, D., Heilman, B. D., Miaoulis, L. N., "Insect thin films as solar collectors", Appl Opt. 33(28), 6642-7 (1994).

[83] Parker, A. R., Mckenzie, D. R., Large, M. D. J., "Multilayer reflectors in animals using green and gold beetles as contrasting examples", J Exp Biol., 201(9), 1307-1313 (1998).

[84] Vigneron, J., Pasteels, J., Windsor, D., et al., "Switchable reflector in the Panamanian tortoise beetle Charidotella egregia (Chrysomelidae: Cassidinae)", Phys Rev E., 76(3) (2007).

[85] Goldstein, D. H., "Polarization properties of Scarabaeidae", Appl Opt., 45(30), 7944 (2006).

[86] Arwin, H., "Application of ellipsometry techniques to biological materials", Thin Solid Films., 519(9), 2589-2592 (2011).

[87] Sun. J., Bhushan, B., Tong, J., "Structural coloration in nature", RSC Adv., 3(35), 14862 (2013).

[88] Yu, K., Fan, T., Lou, S., Zhang, D., "Biomimetic optical materials: Integration of nature's design for manipulation of light", R Soc Chem Adv., 3, (2013).

[89] Bhushan B., "Biomimetics: lessons from nature--an overview", Philos Trans A Math Phys Eng Sci., 367(1893), 1445-86 (2009).

[90] Bar-Cohen, Y., "Biomimetics: Biologically Inspired Technologies", CRC Press, Boca Raton (2005).

[91] Chen, Y., Gu, J., Zhu, S., Fan, T., Zhang, D., Guo, Q., "Iridescent large-area ZrO[sub 2] photonic crystals using butterfly as templates", Appl Phys Lett., 94(5), (2009).

[92] Vukusic, P., Kelly, R., Hooper, I., "A biological sub-micron thickness optical broadband reflector characterized using both light and microwaves", J R Soc Interface, 6, 193-201 (2009).

[93] Watson, G. S., Blach, J. A., "Characterisation of cuticular nanostructures on surfaces of insects by atomic force microscopy: mining evolution for smart structures". SPIE's International Symposium on Smart Materials., 378-385 (2002).

[94] Stoddart, P. R., Cadusch, P. J., Boyce, T. M., Erasmus, R. M., Comins, J. D., "Optical properties of chitin: surfaceenhanced Raman scattering substrates based on antireflection structures on cicada wings", Nanotechnology, 17(3), 680686 (2006).

[95] Mandelbrot, B., "Fractals : a geometry of nature : fractal goemetry is the key to understanding chaos. It is also the geometry of mountains, clouds and galaxies", New Sci., 127(1734), 38-43 (1990).

[96] Goldstein, D., Goldstein, D. H., "Polarized Light, Revised and Expanded", Marcel Dekker (2003).

[97] Åkerlind, C., Arwin, H., Hallberg, T., Kariis, H., Landin, J., Järrendahl, K., "Scattering and Depolarization Properties of Natural Structures - Optical Studies of the Beetle Cyphochilus insulanus", American Vacuum Society 58th Conference, Nashville. American Vacuum Society (2011).

[98] Arwin, H., Berlind, T., Johs, B., Järrendahl, K., "Cuticle structure of the scarab beetle Cetonia aurata analyzed by regression analysis of Mueller-matrix ellipsometric data", Opt Express, 21(19), 22645-56 (2013). 
[99] Hodgkinson, I., Lowrey, S., Bourke, L., Parker, A., McCall, M. W., "Mueller-matrix characterization of beetle cuticle: polarized and unpolarized reflections from representative architectures", Appl Opt., 49(24), 4558-67 (2010).

[100] Askar, K., Phillips, B. M., Fang, Y., et al., "Self-assembled self-cleaning broadband anti-reflection coatings", Colloids Surfaces A Physicochem Eng Asp., 439, 84-100 (2013).

[101] Parker, A. R., Hegedus, Z., "Diffractive optics in spiders", J Opt A Pure Appl Opt., 5(4), 111-116 (2003).

[102] McPhedran, R., Nicorovici, N., McKenzie, D., et al., "Structural colours through photonic crystals", Phys B Condens Matter, 338(1-4), 182-185 (2003).

[103] Chun, W., Liu, X., Xuan-jun, W., "A novel low infrared emissivity material by Ni-P-CB electroless nanocomposite", Adv Mater Res., 79-82 (2009).

[104] Wang, T., He, J., Zhou, J., et al., "Microwave absorption properties and infrared emissivities of ordered mesoporous CTiO2 nanocomposites with crystalline framework", J Solid State Chem., 183(12), 2797-2804 (2010).

[105] Wang, T., He, J., Zhou, J., et al., "Electromagnetic wave absorption and infrared camouflage of ordered mesoporous carbon-alumina nanocomposites", Microporous Mesoporous Mater., 134(1-3), 58-64 (2010).

[106] Hapgood, F., "Metamaterial revolution: The new science of making anything disappear", Discov. Mag., (2009).

[107] Gaspar Venancio, L. M., Hannemann, S., Lubkowski, G., et al., "Metamaterials for optical and photonic applications for space: preliminary results", SPIE Optical Engineering + Applications. International Society for Optics and Photonics (2011)

[108] Brückner, J., Le, J., Escoubas, L., et al., "Metamaterials for visible and near infrared antireflective properties and large surface elaboration", SPIE Proc. 8619, 1-16 (2013)

[109] Peters, D. W., Davids, P., Wendt, J. R., Cruz-Cabrera, A., Kemme, S., Samora, S., "Metamaterial-inspired highabsorption surfaces for thermal infrared applications", SPIE Proc. 7609 (2010).

[110] Chen, P-Y., Alù, A., "Mantle cloaking using thin patterned metasurfaces", Phys Rev B., 84(20) (2011).

[111] Andersson, K. E., Bang, M., Marcus, C., et al., "Military Utility, a proposed concept to support decision-making", In manuscript, (2014). 